\title{
Translations: Artifacts from an Actor-Network Perspective
}

\author{
by John Shiga, Carleton University
}

iPods, MP3s and file-sharing networks perform a series of actions that are often reserved for human agents, such as the intellectual and taste-driven labor involved in selecting, sequencing, and rediscovering forgotten sound recordings. At the same time, the familiar understanding of artifacts as stable, material, objective things "out there" is also being eroded by the infinite replicability, malleability, and ephemeral flickering of things online. These trends lead to questions regarding the ontological status of artifacts and reopen the question of how to distinguish technical and material artifacts from human and social relations. In this article, the author explores actor-network theory's (ANT) concept of translation, which advances an alternative framework for understanding the role of artifacts in everyday life.

Keywords: Actor-network theory, Nonhuman agency,Politics of design, Digital audio, File-sharing, Copyright law

\section{INTRODUCTION: DO ARTIFACTS “ACT"?}

In the overlapping designs of compression algorithms, online music distribution systems, MP3 players, and features like random shuffle, there is a new space opening up for popular, journalistic and academic discussions of the activeness of artifacts in social and cultural life. These trends raise important questions concerning the ontological status of artifacts: How can we distinguish technical and material artifacts from human and social relations? How do we locate agency in a world where capacities to act are distributed across a wide array of materials? In order to recognize the role of artifacts in constituting the social world, do we need a notion of nonhuman agency? Using industry statements, news reports, and technical papers on iPods, data compression codecs, and copy protection techniques, this article demonstrates how actor-network theory (ANT) provides a useful framework for engaging with these foundational questions regarding the role of artifacts in contemporary life. The article begins by reconstructing ANT around the concept of translation, a step which, I argue, is necessary in order to redirect analytic attention to the processes through which claims about society, nature, and technology are transformed into facts and artifacts. Despite the rhetoric of dematerialization and virtuality, I argue that the ANTian concept of artifacts as embodied actions and knowledges remains useful for studying the politics of online artifacts. The article then turns to the controversy in the sociology of science and technology concerning nonhuman agency. ANT's notion of nonhuman agency is distinguished by its ontological claim that the social world is constituted by humans and artifacts and that society should therefore be studied symmetrically with regard to human and nonhuman entities. Finally, the article attends to critiques of nonhuman agency that have important implications for the application of ANT's notion of artifacts as associations of heterogeneous entities to the study of digital artifacts and technologies.

\section{RECONSTRUCTING ANT}

\section{AROUND THE CONCEPT OF TRANSLATION}

What is today referred to as actor-network theory or ANT was initially called the sociology of translation. As ANT became increasingly popular in sociology and other fields in the late 1980s and 1990s, the notion of translation receded to the background (Latour, 1999a; Law, 1999). Both concepts were developed to stress the heterogeneity of the social world, the distribution of agential properties across the human/ nonhuman divide, and the processes through which socio-technical collectives extend themselves. ${ }^{1}$ However, when divorced from the concept of translation, the actor-network becomes at best a synonym for other kinds of social, technical, or communication networks and at worst a restatement of the agency-structure debate. ${ }^{2}$ By relocating translation closer to the centre of ANT, this section attempts to recover the ANTian conception of agency as a distribution rather than as a fixed property of certain entities. ${ }^{3}$ The linguistic metaphor of translation emphasizes the manner in which entities' interests, goals, or desires are represented, simplified, and transformed in the production and mobilization of artifacts. Reconstructing ANT as a theory of translation puts into view the distributional processes through which knowledge and action come to be embodied by a collective of humans and artifacts. ${ }^{4}$ 
In early ANT literature, translation refers to a process through which one or a few actors become spokespersons for a multitude of others by defining and linking their identities in increasingly simplified and fixed forms. The concept of translation was quickly adopted and transformed into a broader theory of social order and power by a group of sociologists of science and technology, most notably Bruno Latour, John Law, Madeleine Akrich, and Michel Callon. ${ }^{5}$ These theorists offered the sociology of translation as an alternative to constructivist and realist explanations of scientific knowledge, which require the analyst to take either "nature" or "society" as a given (Callon \& Latour, 1992). As John Law argues:

[Sociologists] talk of the social. And then (if they talk of it at all which most do not) they talk of the technical. And, if it appears, the technical acts either as a kind of explanatory deux ex machina (technological determinism). Or it is treated as an expression of social relations (social reductionism). Or (with difficulty) the two are treated as two classes of objects which interact and mutually shape each other. (1991, p. 8)

The theory of translation was developed to overcome these problems in sociological approaches to science and technology. It was introduced to English-speaking audiences with the translation of Callon's (1980) essay on scientific problematization, a process that he studied in the development of a public-private research program on electric vehicles in France. ${ }^{6}$ Callon $(1986 a, b)$ later defined problematization as the first stage in a series of actions by which an actor makes itself indispensable to others.
To make entities accept the inter-definition of their identities in the problematization, the principal actor uses various strategies and devices of interessement. Seduction, force, and persuasion, for example, may be used to stabilize the entities' identities, set parameters for their interaction and cut them off from alternative definitions of their identities (CalIon, 1986b). These tactics, if successful, lead to the enrolment of entities within a program of action. The definitions of interests, goals, and identities are then mobilized through representational techniques and the physical displacement of entities. In general, the process of translation tends towards the association, combination, and simplification of entities and the reduction of representatives to one or a few actors. It transforms weak, provisional, and generally defined identities into durable and seemingly irreversible ties. If translation is successful, the principle actor "speaks for others but in its own language" (Callon, 1986a, p. 26).

The boundaries between the various stages of translation are perhaps more fluid than Callon's template implies, but it is useful for describing the transformation of claims and projects into technological facts and artifacts in a way that does not take social, natural, or technological reality as givens. Using the framework of translation, attention can be directed towards the transformative processes through which entities are combined and linked with others. As Latour (writing as "Jim Johnson", 1988) put it: "I use translation to mean displacement, drift, invention, mediation, the creation of a link that did not exist before and that to some degree modifies two elements or agents" (p. 32). ${ }^{7}$ While one could use this framework to examine the various functions that
1."In order to describe such heterogeneous worlds and their dynamics in general terms, we introduced the notion of the actornetwork. This concept is important in part because it overcomes the macro-micro distinction: actor-networks may either grow, or decline, in size. Indeed, the strategies of scientists, as well as those of other actors, can be characterized as attempts to make relevant actor-networks grow" (Callon, Law \& Rip, 1986, p 224).

2.0ne might say downplaying the role of the actor-network concept in ANT does more than merely reconstruct ANTand transforms it beyond recognition. But the actor-network concept has been the weak link in ANT's repertoire of concepts, as suggested by Collins and Yearley (1992a, 1992b). Compounding the difficulties of its apparent resonance with "agency-structure", Callon, Latour, and Law frequently use "actor", "agent", and "actant" interchangeably, thus making it all too easy to misunderstand the "network" in "actor-network" as a synonym for "society" or "social structure". Finally, Latour points out that the application of the actor-network concept to digital communication networks has diminished the sense in which actor-networks are composed through the transformation of the "nodes" linked together, and not through the instantaneous transmission of information between nodes (Latour \& Crawford, 1993).

3. In contrast to translation, the actor-network seems to impose a particular topology of agency or agency effects onto the actors (Law \& Mol, 1994) and risks overlooking the way actors use network metaphors themselves, often to exclude and define insides and outsides (Riles, 2000).

4. In addition to the problems mentioned here, the network metaphor imposes a particular shape or structure on social relations. This is completely contrary to ANTian methodology. According to Latour (1999a): “ANT does not tell anyone the shape that is to be drawn - circles or cubes or lines - but only how to go about systematically recording the world-building abilities of the sites to be documented and registered" (p. 21). Indeed, in ANT literature there are countless diagrams and figures that are meant to demonstrate the variability of the shape and form that actornetworks may take (as well as the many possible ways analysts may depict them).

5. Since much of Akrich's work has not been translated into English, I have concentrated primarily on the work of Callon, Latour, and Law. This unfortunately replicates a blind-spot in AngloAmerican work on ANT, which excludes Akrich from ANT's "first wave". In fact, her descriptive techniques and semiotics of machines had a significant influence on ANT (Latour as Johnson, 1988, p. 305-306). See especially Akrich and Latour's (1992) repertoire of terms for describing the association and substitution of action between humans and nonhumans through the use of scripts in material settings.

6.Callon (1991) traces the concept back to work published in 1976, although it has not yet been translated into English. 
an artifact acquires over time, it also directs analytic attention on the stages prior to the emergence of a discrete artifact or self-evident technological fact.

\section{TRANSLATING INTERESTS: ITUNES, IPODS AND MP3S}

According to the theory of translation, it should be possible to trace the iPod, like any other artifact, back to a set of problematizations. As Callon (1980) noted in his study of scientific problematization, these zones of uncertainty are not defined through logical deduction from the existing body of knowledge, nor are they the result of straightforward political or economic influences. ${ }^{8}$ Rather, a heterogeneous array of elements - technical artifacts, notions of what sort of society would need or support the production of portable MP3 players, the attributes of the imagined consumers that would be interested in these artifacts, and so forth - were deployed alongside principles of psychoacoustics and the behavior of different kinds of digital memory in constructing the grids of certainty that frame research problems.

In principle, each engineer in Apple's secretive "digital hub" project could have defined the problematic area differently due to her or his particular position within a set of relationships with laboratories, companies, areas of expertise, and so on. This raises the question of why actors come to accept others' definitions of the problem and the prescribed actions and roles within it. Callon's (1980) answer, which he derives from a combination of textual analysis of laboratory documents and participant observation, is that problematizations follow one another not by logical deduction but by association, or the sociologic of translation. Each problematization is an attempt to "induce consent and provoke resistance in various groups" by defining, equating, simplifying and displacing interests and goals into a set of relations between cognitive and social entities (p. 215). A problematization that states that there are logical links between a set of problems (that their sequential solution will resolve the larger problem defined at the outset) "is to state that a community of interests exists" between a set of groups and, moreover, that "social interaction is conceivable between them" ( $p$. 211). Problematizations for Callon are attempts to define and mobilize social groups while simultaneously constraining the number of possible responses (and sequences of responses) from these groups.

7.Latour (1988) wrote under the pseudonym Jim Johnson in this particular article. The actor-network theorists used the term "translation" in a variety of ways. In some cases, it seems to refer to a stage in a broader process of coordinating and mediating action. In other cases, it is used as a kind of shorthand for the entire process of coordinating action. Latour (1994a) later used translation to refer to a stage in the extension of social fabric to nonhumans. Translation is "the means by which we inscribe in a different matter features of our social order" ( $p$.
Actors deploy strategies that work upon (transform, link, merge, displace) interests in such a way that the other entities consent to the imposition of the problematization because they already appear to be implicated in it. The translation or inter-definition of interests induces consent by proposing relations between problems/groups as well as by accommodating and constraining how the next actor will orient him/herself towards the uncertainty imposed upon it. For example, Apple's expansion into music, video, and photography in the early 2000s revolved around a sequence of problematizations that established Apple as an obligatory passage point for those who wanted to collect, organize, and share digital content. The popular iTunes music software can be traced back to a problematization of technoeconomic reality that initially generated resistance (rather than consent) in the upper ranks of Apple. Sales of portable MP3 players lagged behind the enormous popularity of the MP3 format on the web because, as Apple's vicepresident Greg Joswiak put it, "The product [made by other companies] stank" (Barker, 2005). Tony Fadell, an Internet consultant, modified this problematization: how can MP3 players foster the sale of music online (Barker, 2005)? Fadell's problematization does not simply redefine the problem to be solved but changes the identities of various products and services in a highly strategic way. iTunes becomes an online music service and tool for selling and promoting Apple's other products rather than an application for playing music acquired elsewhere. MP3 players become extensions of an online music store rather than devices for playing music downloaded from file-sharing networks or ripped from CDs.

Legal, economic, cultural, and technological realities were used in the construction of this problematization and durable links were established between seemingly disparate entities (e.g. record companies, soft drink manufacturers, musicians, football fans, and users of unsanctioned file-sharing networks). The enrollment of these entities required the modification of their identities and the use of a variety of means of interessement: seduction, persuasion, and the force of law. Perhaps the most visible device of interessement in this case was Pepsi's "I Fought the Law" Super Bowl advertisement in 2004 in which 16 teenagers sued by the Recording Industry Association of American explained how they could continue to get free music on the Internet by obtaining the

45), setting the stage where nonhumans receive human properties, and are enrolled into and mobilized within the collective. At other times, translation is used to refer to this whole process of collective formation, modification, and movement/action, as in the "socio-logic of translation" (Callon, 1980).

8.Latour \& Woolgar (1979/1986) similarly found that money itself was not the motivation for scientific activities, even though actors consistently understood their work, associations, and productions as investments. 
winning codes printed on soft drink caps and redeeming them at Apple's iTunes music store (Walker, 2004, p. F07). Apple thus sets itself up not so much as a computer hardware/software company but as an obligatory passage point for those seeking "free music". Subscribers to competing music services were attributed with interests, wants, and desires that were only partially fulfilled by these other music services. As iTunes marketing director Peter Lowe put it, "They want to have the flexibility to do what they want with it. They don't want to rent music" (Ryan, 2003). Apple also set itself up as an obligatory passage point for the music industry by reducing the industry's identity to certain legal, economic, and technological problems, such as "shrinking revenues, downsizing work forces, and the threat of extinction from an apparently unstoppable force called downloading" (Barker, 2005). The most important point here is that the goals of the principal actor drift as increasing numbers of entities are drawn into the program of action. In this case, Apple's goals drift from the production of computers and software towards the sale of digital music and the development of a line of portable MP3 players.

Before a collective can be mobilized, the links between entities and the summarization of their interests through representational chains (e.g. statistical analyses, prototypes, etc.) have to be tested. Will file-sharers pay for music? Do subscribers to music services really want to "own" rather than "rent" music? Will record companies accept their role as "content providers" and relinquish their oligopolistic control over the system of distribution? In this case, all the entities accepted their roles with one exception: the iPod. The portable MP3 player drew power from the batteries even when it was switched off. As one engineer put it, "The production lines had already been set up. That was a tense part of the project. For eight weeks they thought they had a three-hour MP3 player" (Barker, 2005). To persuade the iPod to accept its role as a portable player with vast memory and a long battery life, one of its characteristic design features - a small hard drive with a relatively large storage capacity - had to be compromised. The result was that the iPod did not differ radically from other MP3 players since it too required a dose of flash memory to overcome its hunger for power.

The last part of this analysis would be highly problematic for some social scientists on a number of grounds. First, it suggests that power is exercised upon nonhuman entities and that they are therefore sites of potential resistance. This does not conform to widely held conceptions of agency in the social sciences as residing within the human universe, not that of "things". Second, one might point out that the tactics of interessement are deployed by human actors (e.g. Apple's CEOs, marketing directors, etc.) and that counting the number of iPods that work for
10 hours as opposed to those that work only for three does not amount to a kind of nonhuman "vote" for the program of action. While artifacts may in certain ways "act", sociologists are hesitant to refer to them as social actors since they lack the (human) capacity to choose between various courses of action according to their intentions or interests. Finally, it could be argued that notions of nonhuman agency diminish the capacity of analysts to trace the origins or causes of collective action and therefore undercut attempts to make people accountable for their actions and those of their artifacts.

ANT does not deny that there are differences between human and nonhuman entities, but it does challenge the asymmetrical view of the social world as constituted by human actors who impose their will upon passive artifacts. As Callon explains:

Considered from a very general point of view, [translation] postulates the existence of a single field of significations, concerns and interests, the expression of a shared desire to arrive at the same result. Though translation recognizes the existence of divergences and differences that cannot be smoothed out, it nevertheless affirms the underlying unity between elements distinct from one another. Translation involves creating convergences and homologies by relating things that were previously different. (1980, p. 211)

The performance of a particular definition of reality depends on the strength of the links between heterogeneous entities and their enrolment and mobilization into a singular course of action. When the iPod's hard drive behaved differently from the way it had been represented, it threatened to shut down the assembly lines as quickly as they had been set up. Our understanding of artifacts can be enriched by attending to the possibilities of resistance that emerge from the representation and imposition of identities on entities that seem merely technical. In this framework, Latour (1999b) writes, "the prime mover of an action becomes a new, distributed and nested series of practices whose sum can add up but only if we respect the mediating role of all the actants mobilized in the series" (p. 181). By replacing the sociological notion of actor with the semiotic notion of actant, we have a framework in ANT for understanding agency as a set of capacities that are structured like a language and which can therefore be translated into various material settings. The next section explores the implications of this concept of agency for "virtual" artifacts.

\section{DIGITAL ARTIFACTS, MATERIALITY, AND POLITICS}

Along with other fields and disciplines, media studies has recently become concerned with the cultural, political, and economic consequences of the dematerialization of artifacts in online environments. As Don Slater (2002) observes: “The over-arching 
claim of much of that literature has been that this dematerialization - in particular, the purely textual presence of interacting participants, cut loose from material bodies and places - has allowed the possibility for creating new forms of social order and identity" (pp. 227-228). ${ }^{9}$ If, as Andreas Reckwitz (2002) claims, ANT was an attempt to redeploy materiality in cultural theory and to rethink materiality in terms of artifacts, then the emancipatory rhetoric surrounding dematerialization and virtuality may pose a formidable challenge to the application of the theory of translation to the study of online artifacts. In this section, I argue that the theory of translation remains relevant to the study of the politics of digital artifacts. An analytic framework based on translation examines the design of digital artifacts as the exchange of actions, skills, goals, and capacities between human and nonhuman entities, what John Law (1991) calls "heterogeneous engineering" ( $p$. 9). Such a notion of design, it seems to me, is much more relevant to the kinds of sociality, power techniques, and empowerment networks emerging from contemporary socio-technical collectives.

The theory of translation leads to a quite specific notion of artifacts as constituents of (rather than supplements to) the social world. However, the theory of translation postulates a form of nonhuman agency that is distinct from that of posthumanism and cyborgism wherein nonhuman agency is understood to be a relatively recent cultural phenomenon. As Latour puts it:

The name of the game is not to extend subjectivity to things, to treat humans like objects, to take machines for social actors, but to avoid using the subject object distinction at all in order to talk about the folding of humans and nonhumans. What the new picture seeks to capture are the moves by which any given collective extends its social fabric to other entities. (1996b, p. 194)

Design is a political activity because it breaks down a program of action into little scripts (or prescriptions) which are distributed across, and embodied by, the heterogeneous materials that compose the social world. The production of an autonomous agent, whether human or nonhuman, machinic or virtual, complex or simple, is produced through the attribution of collective action to a relatively few "point locations", that is, "places or points that last, that keep on going for a time" (Callon \& Law, 1995, p. 497). An actor, regardless of size, complexity, or

9.Lawrence Lessig's work $(1999,2002)$ provides a cautionary note against the utopian strand of literature on digitalization. Lessig has repeatedly argued that creative uses of online artifacts such as MP3 files are constrained and monitored in an unprecedented way through software patents and copyright law and through the technical codes that regulate social species, begins to acquire agency (capacities to perform a list of actions) through the primary translation mechanism in which a principal actor forms associations with other entities. Agency may be ascribed to a point within that collective through a secondary mechanism of translation. This secondary mechanism has no necessary relation to the primary mechanism (Latour, 1987). In other words, attributions of responsibility, accountability, and intentionality do not always reflect the actual processes through which the collective action was composed in the first place. In this sense, an actor is a network; its identity is constituted by its epistemic relations with "others" that persist over time (Hetherington, 1997, p. 195).

According to Jon Rubinstein, the senior vice-president of hardware development at Apple who assembled the design team for the first version of the iPod, the development of the iPod "started with a clean sheet of paper" (Schlender, 2001). The blank page implies that the iPod was dreamt up and realized by Rubinstein and his design team without borrowing ideas, theories, technical components, and expertise from other places. The secondary mechanism is evident in Rubinstein's account, since he is suggesting that the iPod was built from scratch by a few talented humans. But his account erases key processes in the primary mechanism of translation. For instance, one of the crucial tactics of interessement that led to the enrolment of file-sharers was the compatibility of the iPod with music files encoded in the MP3 file format. Focusing on the primary mechanism of translation takes us past Rubinstein's "clean sheet" to the messy world of MPEG-1 Audio Layer 3, or MP3.

Given all the talk about dematerialization, it is interesting that digital artifacts, like any technical innovation, leave long paper trails behind them as they emerge. In the case of MP3, the paper trail is enormous, spanning across the news media, law journals, computer science articles, patent claims, and legal decisions. Much of this literature construes the politics of MP3 in terms of legal controversies over ownership and public access. But one does not need to concentrate on corporate or legal influences on copyright legislation or legal decisions to discern the power relations of MP3. "The social" does not intrude upon "the technical" periodically. To break the world up in this way would be to accept the modernist notion that science and technology can and should be purified of politics. Translation theory suggests instead that attempts to order the world, including the most specialized technical and and cultural activities online. In Lessig's view, the reduced malleability and constrained replicability of online artifacts is a consequence of the imposition of economic interests by certain powerful human actors, in particular, "largish" entertainment conglomerates that seek to maximize their control over the circulation and use of online artifacts (Lessig, 2002, chap. 11). 
scientific papers, are not disinterested activities but rather are highly strategic attempts to bind humans and nonhumans together and make them accept particular definitions of their capacities, roles, and identities.

In Langdon Winner's (1980) oft-cited article on the question of whether or not artifacts have politics, he argued that the social determination of technology overcompensates for technological determinism and leads to its own impoverished notions of causality. Social determinism suggests that "technical things do not matter at all ... there is nothing distinctive about the study of technology in the first place" (p. 122). Winner offered an alternative framework based on the notion that the politics of artifacts can be analyzed by looking to the things themselves. In contrast, the theory of translation, as discussed in the previous section, troubles this view of technologies as "brute material artifacts" (Callon \& Latour, 1992) that are political only insofar as they set constraints on human relationships (Latour, 1994a, 1999b). The thrust of ANT case studies is this: the politics of artifacts should be reconceptualized to account for the actions that are routinely distributed or shifted between humans and nonhumans in the practices of scientists, technologists, and users. Each of these heterogeneous engineers acquires allies and draws power from them by transforming "natural" differences between humans and nonhumans into distributions (Law, 1991). ${ }^{10}$

Without the proliferation of unsanctioned MP3 sites, anti-piracy campaigns, and efforts to build security features and copy protection features into music files, would MP3 have politics? Using the framework of translation, we can answer "yes". MP3 is political not because it has led to juridical and technical constraints on human interaction but because it requires a redistribution of capacities across the human/nonhuman divide in order to empower a hybrid collective. To trace out the politics of MP3, we need to revisit the scientific problematizations that established alliances and possibilities of interaction between entities. The effect of these problematizations, according to Callon (1980), "is not to create stability and order. It is to create local instability. With the creation of such instability the possibility of autonomy arises" (p. 217).

In 1988, the International Standards Organization established a committee (ISO/IEC JTC1/SC29 WG11), which was called the Motion Picture Experts Group or MPEG (Brandenburg, 1995). Chaired by Hans
Musmann, MPEG developed a series of audiovisual encoding standards. While Charles Creusere (2003) notes that digital audio compression has been a persistent problem for the telecommunications industry since the 1970s, MPEG interested a wide variety of firms and engineers by developing a new problematization. As Musmann (1990) argued, "A coding technique which allows to reduce the bit rate of a stereo sound signal down to $2 \times 128 \mathrm{kbit} / \mathrm{s}$ or even to $2 \times 64 \mathrm{kbit} / \mathrm{s}$ preserving a sound quality comparable to that of CD would be very attractive to save transmission and storage capacity and would facilitate the introduction of new services" (p. 511). Musmann sets up a problem (How can sound be digitally represented using less data than CD encoding but with the same sound quality?) and a grid of certainties (particular input and output sampling rates, lower bit rates, and so forth are necessary) to outline the "hunting grounds" or areas to be analyzed by groups of engineers. Musmann then associates these problematized areas of the cognitive field with particular coding concepts that were developed and tested by groups composed of engineers employed by different electronics firms.

MP3 - the audio layer of the MPEG-1 compression standard-emerged within this socio-cognitive network of problematization. MPEG-1 was the first ISO standard for audio compression, published in 1992 (Creusere, 2003). This standard was accepted not so much because it was more efficient than other proposals, but because its proponents persuaded their colleagues to change the definition of efficiency. Until the emergence of MPEG, efficient compression was defined by the maximum reduction of "quantization noise", noise that results from the conversion of a continuous signal (analogue) into discrete bits (digital). The MPEG group adopted an entirely different way of compressing data by allowing or injecting as much quantization noise as possible, that is, by associating the coding scheme with a perceptual model imported from psychoacoustics. By 1995, Rault et al. confidently asserted that "it is world-wide accepted that the more efficient audio compression algorithm is the one that introduces the maximum noise provided that it remains perceptually inaudible" (p. 3/1). The bit-reduction techniques developed by MPEG were based on the psychoacoustic fact that a sound can be "masked" by a louder sound. The representation of human hearing in the psychoacoustic model was then shifted or inscribed into the codec (decoder/encoder) in order to "exploit the fallibility of the human ear" (Carey \& Wall, 2001, p. 36).
10.The clearest example of this point is in Latour's (1988) study of Louis Pasteur's mobilization of France (and much of the rest of Europe) into a program of action which, at the time, would have seemed like a rather extreme measure (injecting people with fluids; heating all fermenting drinks, etc.). The success of Pasteurization cannot be reduced to the sheer force of his discovery but is a result of modification of identities and the establishment of links between humans and nonhumans. Sickness, for example, is caused by material overlaps between species. Although bacteria occupy a different place in moral, political, and ethical orders, they are usefully understood as distributions across the human/nonhuman divide. The social world was redefined in terms of groups formed by that distribution (the sick, the infected, the contagious, the immune, etc.). 
The politics of MP3 are not reducible to the legal controversy surrounding some of its uses on the Internet. Scientific controversies concerning coding techniques, bit-rates, definitions of efficiency and so forth destabilize local areas of knowledge to interest and enlist others in the performance of a particular definition of reality. This does not mean that the politics of science is reducible to the standardization or rationalization of hearing. Long before the legal controversy erupted, Musmann's (1990) report on the ISO plan to develop a compression standard clearly stated that the act of hearing could be divided into scripts (codes, models, algorithms) which would then be distributed to various human and nonhuman entities.

The redistribution of hearing in the development of MPEG codecs is an exercise of power. First, it establishes a grid of certainties about a phenomenon of vibration (i.e. sound) to develop an obligatory passage point (i.e. maintaining tonal relations despite compression). Accepting the problematization means accepting a framework for interaction with the other MPEG working groups. MPEG thereby sets itself up as an obligatory passage point for Phillips, Matsushita, and other firms to solve their problems regarding data storage, data transmission, and the development of new services. Second, each coding concept is a claim about the acceptable amount of data that can be lost in the encoding stage and the amount of noise that can be "injected" into digital recording without affecting its "subjective quality". To bolster these claims, the working groups embedded them in a collective (or network) of private and public institutions, mathematical theories of data compression, acoustic facts, and artifacts such the filtersbanks, integrated circuits, and chips that encode and decode digital representations of sound (Rault et al., 1995). The engineers enrolled a psychoacoustic model of human hearing, which they associated with their various coding and bit-allocation techniques. The fact that sounds can be masked by other sounds was translated into an encoding technique called psychoacoustic masking. Since no one contested psychoacoustic masking, it acted as a black box. Inside this black box, there were many previous translations including a model of sound based on certain components of the human ear, the summarization of "subjective quality" in perceptual audio codes, and the notion of efficient compression as the maximization of imperceptible noise. This model was crucial to the distribution of the capacity to hear within the hybrid collective.

Compression algorithms are not political simply because they impact on social organization or because they are inscribed with the normative values of a corporate engineering community. MP3 embodies representations of the (vibrating) world and definitions of efficiency which render the "lossy" compression format acceptable, desirable, and una- voidable. MPEG also enrolled a number of previous translations such as the psychoacoustic model of hearing, which abstracts the senses, detaches the ear from the body, and treats sound as an object that can be controlled, chopped up, reassembled, and injected with noise. Finally, MP3, like all sound reproduction technologies, does not merely depend on the extension of human hearing but rather, as Jonathan Sterne (2005) puts it, "on us delegating to machines that hear for us" (p. 41).

The question that remains is whether or not artifacts delegate capacities or tasks back to humans. In the next section, I examine how the application of political notions of delegation, spokespersons, representation and so on led to a shift in ANT from quasianthropological studies of science and technology towards a controversial theorization of society as an association of human and nonhuman entities. In short, we move from a notion of nonhuman agency as an effect of human attributions of agency to artifacts towards a notion of agency that is inseparable from the distribution of action across heterogeneous materials.

\section{THE RESISTANCE AND REPRESENTATION OF ARTIFACTS}

Since ANT attempted to theorize artifacts as distributions of actions across heterogeneous materials, it leads to certain questions about resistance: Do human and nonhuman entities always accept these provisional ties instantiated in the design of an artifact? Are "actants" equal in their capacity to resist their spokespersons? More fundamentally, does the notion of nonhuman agency detract from the study of empowerment and resistance in social organization? Steve Fuller (as cited in Barron, 2003) finds the absence of human resistance in ANT literature very disturbing: "The whole point of social organization is specifically to combine in ways that go against the natural course of things. In that sense, resistance and conflict are what characterize the distinction between the human and the non-human" (p. 83). Fuller thus takes the ANT researchers to task for failing to address the capacity of humans to resist those who attempt to order, engineer or design interactions between humans or between humans and nonhuman entities.

Are humans distinguished by their capacity to resist "going with the flow"? Is this what artifacts cannot do, no matter how sophisticated they may be in their other capacities? In Fuller's view, yes. To complicate this view, however, ANT argues that nonhumans may also contest the apparent unity of the artifact or design. The resistance of nonhumans is evident in Latour's (1987) study of the Diesel engine, particularly during its mobilization through patent law, promotion, cultural and industrial use: "The reality of the engine receded instead of progressed.... From a factual artefact it became, if I may use the two meanings at 
once, an artefactual artefact, one of those dreams the history of technics is so full of" (pp. 105106). Nonhumans are not easily persuaded into relations with each other or with human beings. As my discussion of the development of the iPod suggested, nonhumans can "defect" from the coordination of roles set out in business plans, blueprints, prototypes, and promotion; hard drives may demand too much power and batteries can go "on strike", shutting down the assembly lines. But the notion that the defection of the hard drive from the iPod amounts to a form of resistance is deeply troubling for some researchers because it blurs the foundations on which studies of resistance and power in science and technology have traditionally been carried out. By exploring the hostility in the social sciences towards the idea of nonhuman resistance, this section elucidates the conceptual boundaries within which artifacts are permitted to act in conventional sociological explanations of technology.

The claim that artifacts "act" may not raise many eyebrows in the social sciences insofar as it is accompanied by a recognition that this kind of action differs in important ways from human action. Agency is a relational concept because it refers to the capacity to perform a particular action or set of actions. Agency also seems to vary according to species because entities have different capacities in the realm of action. In the case of humans, agency is usually associated with the capacity to make the world meaningful (Casper, 1994), to constitute representations (Smart, 1982), or to shape the world according to one's intentions (Bruum \& Langlais, 2003). More fundamentally, human agency is distinguished by the capacity to choose between different courses of action. According to Henrik Bruun and Richard Langlais (2003), “Within the social sciences, agency is often associated with the power to choose, that is, to the power to act in one way even though one could have acted differently" (p. 33).

In this view, it is extremely problematic to suggest that artifacts have the capacity to resist the tasks delegated to them, to exert force upon the manner in which they are represented, or to decide how to make the world meaningful. Nevertheless, artifacts seem to display some of these agential properties. According to one iPod user, "There is something thrilling about setting the player on Shuffle and letting it decide what to play next. The little machine often goes crashing through barriers of style in ways that change how I listen" (Kahney, 2004). Michael Bull, who has written extensively about the way personal stereos like the Walkman enhance the user's sense of control over her or his environment, mood, and subjective behavior, has found that users attribute agency to the iPod: "Some users feel that the machine intuitively understands them by giving them just the type of music they want to listen to when they want it" (Kahney, 2004). Bull's descrip- tion conforms to the notion of human agency in the social sciences ("users feel that... ") even though the other action verbs ("decide", "understands", "giving") point to a form of nonhuman agency. The distinction between human and nonhuman action, and the privileging of the former, enables social researchers to maintain critical distance from their research subjects. But since this distinction is routinely disregarded by technologists and users, researchers are faced with the problem of how to integrate these accounts of nonhuman agency into their understanding of artifacts. Are users mistaking the actions performed by artifacts with the human capacity to choose between actions? Is the analyst's role to unveil the objective social forces that generate the illusion of iPods as artifacts that act?

In conventional sociology, and in Western culture more generally, agency depends on both intentionality and language use, neither of which was considered to be a property of "things" (Callon \& Law, 1995, p. 490). At the same time, many human actions are constituted by materials outside the human body. ANT researchers were interested in the possibility that agential properties emerge from the material overlaps between human and nonhuman action and that technological design is about arranging, regulating, and exploiting these overlaps through representational techniques. The term "actor" obscures the distribution of actions, deflecting attention to the human origins and causes of action." Thus, a term other than "actor" was required to talk about the heterogeneous embodiments of action. According to Latour (1987), "both people able to talk and things unable to talk have spokesmen [sic]. I propose to call whoever and whatever is represented actant" (p. 84). The term "actant" allows the researcher to set aside the question of origins and causes of social action and examine the techniques of representation, association, and combination through which actions are distributed and embodied by various kinds of materials in addition to the human body.

There are two key senses in which artifacts act in ANT. The first sense of nonhuman agency derives from ANT's methodology and is congruent with more conventional sociological approaches to "things". However, over time, ANTian case studies gave rise to ontological claims about nonhuman agency, which have generated considerable resistance within the sociology of science and technology. ${ }^{2}$ Following Foucauldian notions of power as dispersed through bodily techniques, Law (1986b) suggested that agency in the case of the Portuguese expansion in the sixteenth century needs to be understood as a network of heterogeneous embodiments of knowledge that formed a "protective envelope" around Portuguese ships in uncharted waters. Only in conjunction with mariners drilled in astronomy and modifications in ship design did the printed documents (maps, logs) acquire such tremendous importance in the way the 
Portuguese "interacted" with (and exercised power upon) others without actually occupying their territories. ${ }^{13}$ Rather than viewing the roles of humans and nonhumans in the constitution of the social world asymmetrically, Law's account of the Portuguese expansion tilts towards a symmetrical view of the social world as constituted by humans and artifacts.

ANT's concept of nonhuman agency thus arises not only from empirical studies of scientific knowledge practices, but also from its ontological claims that were designed to show the impossibility of a social order like our own without artifacts that embody and perform certain practical knowledges, competences, or skills. Latour's (1994a) genealogy of techniques made this project explicit in his claim that a society characterized by divisions of labor, tremendous increases in scale, and so on, is only possible through translation techniques, here understood as the socialization of nonhumans whereby scripts for social action are embodied and performed by nonhuman entities. The ontological and historical claim concerning the agency of artifacts became increasingly apparent in ANT literature in the 1990s. ${ }^{14}$

The notion of translation as the socialization of nonhumans was a response to an ambiguity in notion of the "social construction of technology" and social deterministic views of artifacts more generally. ANT bypassed the question of how social relations are mediated by artifacts to examine the more fundamental question of why artifacts proliferate in human societies. "If artifacts are social relations, then why on earth has society to pass through them to inscribe itself onto something else?" asks Latour (1994b).

"Why not inscribe itself directly?" (p. 793). Many of Latour's works provide extended responses to this question. The following passage captures the "quandary" most eloquently in his account of how Rudolf Diesel struggled to transform a mutable and isolated project into an immutable and mobile artifact:

\begin{abstract}
If Diesel is the only person who believes in his perfect engine, the engine sits in an office drawer in Augsburg. In order to spread in space and to become longlasting they all need (we all need) the actions of others. But what will these actions be? Many things, most of
\end{abstract}

11. In the sociological concept of "actor", agency is unquestionably located in the human universe, not that of things (Pels et al., 2002, p. 2; Hetherington \& Law, 2000).

12."As a principle of methodological symmetry", Alex Preda (2000) writes, "it just states that the sociologist has to analyze the human beings and artifacts embedded in such a nexus as knots of socially sanctioned (and primarily tacit) knowledge, and that these kinds of knowledge are contingent upon each other" (p. 286). Preda notes that a variety of approaches including ethnomethodology and the practice theory of Pierre Bourdieu accept this methodological principle and view things as social actors insofar since they act as "knowledge-bearers". them unpredictable, which will transform the transported object or statement. So we are now in a quandary: either the others will not take up the statement or they will. If they don't the statement will be limited to a point in time and space, myself, my dreams, my fantasies.... But if they do take it up, they might transform it beyond recognition. (Latour, 1987, p. 108)

To prevent transformation beyond recognition, one might deploy what Latour calls "social skills" by physically excluding or manipulating bodies (Latour, 1994a). For Latour, however, human societies are characterized by the enrolment of extrasomatic resources into social ties, enabling a particular definition of society to become more durable. Artifacts result from the delegation of social roles to nonhumans that perform provisional bonds between actors: "the durability of the definition of the clan depends upon the duration of the resources used to make it hold together" (1986, p. 275). In this framework, iPods and other "high technologies" are more durable and intimate forms of the same elementary humannonhuman relationship instantiated by the extension of social skills to materials (Latour, 1994a, p. 62). In Latour's (1993) view, high technology can be understood in the following terms:

A shifting network of actions redistributing competences and performances either to humans or non-humans in order to assemble into a more durable whole an association of humans and things, and to resist the multiple interpretations of other actors that tend to dissolve this association. (p. 379)

Artifacts act not just because our research subjects say they do but because the construction and organization of a society requires more durable agents than values, ideologies, or transient interactions between human beings.

The theory of translation (especially the stage of mobilization) postulates that actions have to be physically displaced between bodies, texts, and machines to empower the collective and to increase the durability of particular definitions of society. In this sense, more artifacts have become increasingly socially active over time. However, according to the

13."The right documents, the right devices, the right people properly drilled put together they would create a structured envelope for one another that ensured their durability and fidelity" (Law, 1986b, p. 154).

14.This is particularly evident in Karin Knorr Cetina's notion of postsocial relations, which has been developed on the basis of ANT's arguments about the way science and technology have been crucial sites for the socialization of nonhumans (Knorr Cetina, 1997; Knorr Cetina \& Bruegger, 2002). She argues that the importance of nonhumans in sociality has increased over time due to knowledge practices in science, economics, and elsewhere, and requires a redefinition of social relations. 
theory of the translation, the enrolment of anything/ anyone increases the possibility of resistance or defection. Is nonhuman resistance somehow more "manageable" than that of human beings?

\section{INTELLECTUAL PROPERTY AND IMMUTABLE MOBILES}

The last section suggested that there is an ambiguity in ANT's approach to artifacts. On the one hand, nonhumans are enrolled into social ties because they enable transient interactions, provisional ties, and reversible transformations to become more durable and seemingly irreversible. On the other hand, the enrolment and mobilization of these entities makes the artifact unpredictable and unstable. "To get out of this quandary", Latour (1987) writes:

... we need to do two things at once: to enrol others so that they participate in the construction of the fact; to control their behavior in order to make their actions predictable. At first sight, this solution seems so contradictory as to look unfeasible. If others are enrolled they will transform the claims beyond recognition. Thus the very action of involving them is likely to make control more difficult. The solution to this contradiction is the central notion of translation. (p. 108)

Understood as strategy of translation (or a set of such strategies), design involves the enrolment of others as well as the redistribution, delegation, and fixing of roles to social, natural, and technical entities. ${ }^{15}$ However, according to the theory of translation, as formulated by Callon $(1986 a, b)$, enrolling these nonhumans will also tend to introduce more uncertainty and unpredictability. Any attempt to represent or speak for others is an exercise of power, which opens up the possibility of resistance. In short, translation can lead to "treason" (Callon, 1986b, p. 219). Latour's answer to this problem is that the continuous work of disciplining humans can be replaced by the discontinuous work of installing more nonhumans. "By involving nonhumans", Latour (1994a) asserts, "the contradiction between durability and negotiability is resolved" (p. 61).Whether it is called translation, mediation, or inscription, the process within which nonhumans acquire tremendous importance in social life is the gradual shift in the type of links between entities from "a provisionally less reliable one to a longer-lasting, more faithful one" (Latour as Johnson, 1988, p. 306). In this section, I will demonstrate how this framework, and in particular the notion of immutable mobility, can be

15."Engineers constantly shift out characters in other spaces and other times, devise positions for human and nonhuman us16 CRIA. (2005). http://www.cria.ca/freemusicmyth. php\#mythsanswers. Accessed February 23, 2005. applied to explain the shift from MP3 as a relatively open standard to the development of "copy protection" technologies embedded in digital audio files.

Bruno Latour's $(1990,1998)$ notion of immutable mobility describes the way in which texts and other forms of inscription enable the relations that make up an object to be fixed even while they are mobilized within a network by different actors according to their own projects and goals. The concept refers to techniques and materials of representation such as typographical fixity and linear perspective, which have enabled the creation of larger, more inclusive "meeting places" while at the same time conserving "a constant through successive transformations of the medium" (1998, p. 425). Immutable mobiles allow different entities to be combined, superimposed, compared, simplified, and so forth by accelerating the mobility and by enhancing the immutability of inscriptions. In short, they simultaneously fix knowledge and render it more portable. One particularly important immutable mobile in the cultural industries is copyright law. Copyrights translate cultural practices and works into objects of property; they enable all the materials, techniques, and (most) employees that contributed to an artifact to be black-boxed or forgotten. The results of this collective action - a discrete object like a sound recording - can then be attributed to a legal person, whether an individual or corporation.

In principle, copyright ensures that - no matter what form the work takes - there will be durable relations between the legal subjects and objects of property. However, the proliferation and popularization of filesharing networks have demonstrated how tenuous these relations are in practice, and how dependent these relations are on a supportive environment composed of legal precedents, licensing systems, rights management, drilled clerks, lawyers, and accountable employees. Traveling in MP3 form on the Internet, copyrighted artifacts perform new functions, working, for example, as the currency of peer-to-peer music exchange.

The theoretical immutability of the copyrighted work thus unravels. In practice, each translation of the musical work introduces the possibility that it may defect from its role as an object of property. These displacements can drastically alter the ownership relations embodied by the work. In the case of MP3, the sound object can be altered or simplified to make the file smaller and more easily copied and sent between computers. MP3 maintains the tonal relations of the sound through compression (MPEG's obligatory point of passage), but in order to maintain the links between the subjects and objects of copyright law, ownership relations need to be translated into more durable and mobile forms. For example, when the media conglomerate Bertelsmann bought the Napster file-sharing system in 2002, it also installed 
rights management systems in the network architecture to maintain the ownership relations of copyright. When copyrights travel, they transform the places in which they move, turning them into supportive environments or protective envelopes to maintain the integrity of the representational and proprietary functions of the copyright.

Immutable mobility suggests that the medium does matter. In MP3 form, sound recordings are used differently and towards different ends than they are in the form of CDs or in broadcasting. Similarly, copyrights change and are changed by their movement through different computer networks. We are also beginning to see how the enrolment of MP3s, filesharing networks, and computer users into copyright law alters the way in which ownership relations are maintained. In Canada, the music industry lobby group, CRIA, has attempted to sue the end-users of file-sharing networks, whereas, a few years earlier, commercial pirates were the main targets of such litigation. CRIA has also developed an antipiracy public relations campaign over the last three years targeting Canadian youth, a necessary measure, CRIA claims, because "Consumers have to know that if they want a wide choice and variety of music, that if they want their favourite artists to succeed, they must support them by buying their music". ${ }^{16}$ Until recently, copyright "notices" were inscribed in fine print on CDs in legal jargon. Now they are transformed into multimillion-dollar anti-piracy campaigns designed to capture the interest of the news media, educators, and youth.

\section{File-sharing continues to be a popular cultural} practice in Canada despite the highprofile lawsuits, copyright reforms, and quasieducational anti-piracy programs. CRIA is now faced with two choices since files continue to be swapped long after the message "do not copy unless authorized" has been amplified and translated into various moral and economic discourses: (1) either ensure that everyone reads the order/rule in the same way and responds in the same way, or; (2) "load" the statement by anticipating and incorporating "anti-programs" (Latour, 1991, pp. 104105). CRIA can then make a second translation of the file-sharers' interests (they do not like transferring music from their computer to a CD and back again - a simple but annoying anti-circumvention technique), which leads to a minor technological innovation (copies that regulate their own replication) and a shift in the materials used to enroll file-sharers into the music industry's program of action (digital rights management or “DRM").
Recent technical papers on MP3 compression have set up new problematizations that are designed to interest copyright owners (rather than just electronic firms and telecommunications companies) by translating those interests into the language of compression codecs and metadata (e.g. Egidi \& Furini, 2005; Thorwirth et al., 2000). However, DRM-plus-MP3 does not simply transmit the meaning of the order "do not copy" in a different form to the same entities. The sequence of translations into new material arrangements leads to a gradual shift in the distribution of roles, skills, and competences assigned to the various entities. Rather than pointing towards an already-powerful actor (a class, a corporation, etc.) whose quantitative difference from other actors (having more power, money, prestige, influence, etc.) explains the alignments in the uses of artifacts and thus the stability in the artifact's identity, the emphasis in an ANTian framework is on the local practices through which power is produced by enrolling others into particular definitions of what is practical, unavoidable, or real. ${ }^{17}$

Two important points can be drawn from the attempt to make MP3s more resistant to copying. First, the translation of the statement "do not copy" in anti-piracy campaigns, compression algorithms, and other security devices transforms the interests enrolled by the principle actor and distributes competences and actions to a new configuration of materials, bodies, and machines. The metadata in digital audio files, which controls the number of copies that can be made from the file, internalizes the subject of copyright law who accesses music via his or her computer connected to the Internet. Second, many of the prescribed actions on the web are not read by humans. Like a speed bump, instructions are translated into a form that makes the action of the hybrid person-machine more predictable. The various scenes or settings that one encounters on the web (identity checks, verification tests, blank search fields, etc.) are arranged as seriated actions: "The result of such an alignment of set-ups", Johnson (1988) suggests, "is to decrease the number of occasions in which words are used; most of the actions become silent, familiar, incorporated (in human and nonhuman bodies) - making the analyst's job so much harder" (p. 308). However, as the next section explains, this is not the only difficulty facing ANTian studies of artifacts.

\section{PROBLEMATIZING ANT}

Not surprisingly, since ANT attempted to problematize key sociological methods and concepts, it has been the target of many criticisms. Three of these critiques need to be examined here because they

what 'holds' everyone together. This shift from principle to practice allows us to treat the vague notion of power not as a cause of people's behavior but as the consequence of an intense activity of enrolling, convincing and enlisting" (p. 273). 
have altered ANT's core concepts over the course of the past decade and have affected the way in which scholars study and theorize the role of artifacts using ANTian models: (1) the ontological and epistemological implications of ANT's replacement of the social/technical dualism with the human/nonhuman dualism; (2) the tension between immutability and mobility; and (3) the assumption that artifacts act within already existing places.

Despite its famous methodological slogan ("follow the actors"), some critics have pointed out that ANTian case studies do not adequately attend to the use of artifacts, focusing instead on their construction. The paucity of data related to use was a key reservation about ANT that Collins and Yearley (1992a) put forth in their lively "epistemological chicken" debate with Latour and Callon. The manner in which Collins and Yearley privileged the moment of use as some sort of confrontation between interests or between nonhuman action and human agency can be contested on a number of grounds. However, they correctly pointed to an ANTian tendency over the past two decades to smooth over disjunctures and gaps in the history of technical artifacts. This tendency is most evident in Latour's bold ontological claims regarding the agency of artifacts and their progressive immutability and capacity to form relations with one another:

What [historians] miss, however, is that each of these inventions, of more immutable more mobile elements is creating a new specific type of space that allows them to merge with the other in a specific homogenizing way. The question of their obvious differences is thus less pertinent than that of their ability to tie in with one another. (1988, p. 29)

As discussed in the previous section, the theory of translation offered methodological principles that required the analyst to abandon "all a priori distinctions between natural and social events" and, moreover, to refrain from imposing a grid of identities upon the entities in order to see how "actants" emerge through the distribution of actions in translation (Callon, 1986b, pp. 200201). For Collins and Yearley, this means that ANT obscures the role of the (human) analyst in attributing agency to nonhumans via analytic symmetry. Affirming the determinative role of human action is not only a matter of recognizing the effects of one's own analytic categories and methods upon the subject matter; for Collins and Yearley as well as many other sociologists agency must be recognized as a human property in order to differentiate true and false statements and to trace out the contours and consequences of human action.

18.I refer here to Michel Foucault's (1986) definition of structuralism: "the effort to establish, between elements that could have been connected on a temporal axis, an ensemble of relations
Collins and Yearley worry that nonhuman agency would collapse critical distance in studies of science and technology by relying on scientific expertise to decipher "how much" agency nonhumans have in a given situation.

While Collins and Yearley were defending a particular view of agency in sociology as a uniquely human capacity (an ontological claim), other theorists were more concerned about the implications of ANT's notion of nonhuman agency for epistemology. Monica Casper (1994), for example, noted the merits of taking nonhuman agency seriously by moving beyond the study of human attributions of agency towards the study of how action is constituted by heterogeneous materials. However, she pointed out that such studies are usually premised on "a decontextualized and ahistorical definition of agency" (p. 840). Moreover, assuming a priori that entities are human or nonhuman is problematic since "human is a constructed (and often contested) identity or subject position" (p. 841). Her critique applies to both the ANTian framework and the more conventional approach of Collins and Yearley because neither camp examines the historical specificity of notions of agency. However, her position is closer to that of Collins and Yearley since her concern is with accountability: "in many instances nonhuman agency deflects attention from human accountability to other entities, whether human, nonhuman, cyborg, or what/whomever" (p. 853).

In my view, Casper is critiquing a particular formulation of ANT that became prominent in the 1990s. Initially, the concept of translation enabled analysts to examine the temporality of artifacts by approaching them not so much as products impacting on society, but as processes (e.g. distribution and association) that coproduce social, natural, and technical realties. By the 1990s, the concept of the actor-network became the centerpiece of a theory that transformed relations of time into relations of space. In some sense, the resulting approach resembled a more structuralist approach to the power of science and technology.$^{18}$ Whereas the sociology of translation examined the transformation of identities in the stages of research projects and technological design, the concept of the actor-network implies that identity is determined by a spatial configuration oriented around centers of translation (i.e. laboratories).

The ANT researchers have altered their approach in the wake of such critiques. Latour (1999a,b), for example, attempted to move away from the notion of translation as association and instead used the term "mediation" to examine the exchanges of properties between entities. This emphasis on the traffic that makes them appear as juxtaposed, set off against one another, implicated by each other that makes them appear, in short, as a sort of configuration" (p. 22). 
between entities through which they acquire agential properties offsets the tendency in ANT to think of technoscience in terms of a fixed set of sociotechnical relations and as associations between pre-existing human and nonhuman entities.

While Casper and Collins and Yearley were concerned about the disconnection of agency in ANT with accountability, commitment, responsibility, and intentionality, it is worth pointing out that the theory of translation attempted to topicalize these attributes as processes within the mobilization of hybrid collectives (the secondary mechanism of translation). Accountability is an important element of current legal attempts to re-order the sociotechnical relations of, for example, file-sharing systems on the Internet. While the theory of translation may not offer the necessary tools to contest the manner in which legal systems make individuals accountable for swapping copyrighted sound recordings, it is extremely useful for tracing out the strategies through which collective action is attributed to one or a few individual humans beings. Moreover, it allows the analyst to examine these controversies as contestations of representativity where heterogeneous engineers scramble to develop more sophisticated techniques to speak for and negotiate with an array of entities, many of whom, argues Latour (1987), “do not look like men or women" (p. 121). ${ }^{19}$

Latour's immutable mobile is one of the most popular concepts in the ANTian repertoire. Ironically, immutable mobility has been modified through its movement into various disciplines outside the sociology of science and technology. As discussed in the previous section, the immutable mobile concept suggests that certain artifacts and techniques enable the world to be collected and summarized in durable and portable forms. In contemporary capitalist economies, many artifacts (including software) acquire stability with the aid of immutable mobiles called patents. Patent law translates the messy material activities of design labs and the heated exchanges of scientists engaged in a "proofs race" into the flat, twodimension space of a patent claim. These representations are designed to work like Latour's immutable mobiles since they prescribe roles to human and nonhuman entities

19.In approaching such controversies, the analyst may attempt, as I have done in this article, to trace the actions attributed to individuals back to the alliances established in the primary mechanisms of translation. However, pointing to the heterogeneous materials that perform a particular definition of socio-technical reality does not resolve the problem of representativity. As Latour (1998) points out, “We cannot simply say that 'all of them' count in the making of an observation. If we were stopping at that, something would be missing from the mere deployment of heterogeneous associations" (p. 434). Although ANT advocates a "distributed monism" (Barron, 2003), Latour argues that new distinctions in, for example, the role of the "user" of the invention, or the "public" to whom the patent supposedly discloses the inner working of the invention.

In practice, patent claims are extremely mobile but are not quite as immutable as Latour's concept would suggest. In her study of how patent systems have been deployed in Zimbabwe, Marianne de Laet (2000) uses the notion of the immutable mobile to show how patents are "events that perform connections - and that bring about changes as they go along" (p. 150). However, her ethnographic study of patents in action contests the stability implied by the immutable mobile concept:

Following the tracks of patents into those
worlds renders it strange that in different places patents would be considered the same things. For they emerge in different capacities. They have different effects. They operate in different practices. They ride different vehicles. And they are deliberately used for different purposes. This variety counters the notion that patents are 'single objects', 'immutable mobiles'. (p. 166)

De Laet concludes that this multiplicity "supports a vision of patents as agents in their own right" (p. 166). ${ }^{20}$ However, she argues that immutability obscures the actual manner in which artifacts spread out over time and space. Similarly, Susan Leigh Star suggests that to act like an immutable mobile artifacts need to be "both plastic enough to adapt to local needs and constraints of the several parties employing them, yet robust enough to maintain a common identity across sites" (as cited in Nigel Thrift, 1999, p. 37).

The difficulty in deploying the immutable mobile concept without introducing these important modifications (or mutations) may point to a more fundamental problem in the relationship of artifacts to space and place in the ANT framework. Kevin Hetherington (1997) argues that, while ANT has destabilized the humanist division of place and space and enables analysts to engage with agency as distributions, the notion of immutable mobility "tends to leave the question of the places involved as already established prior to this network of heterogeneous agents" (p. 188). Building on Latour's formulation,

are necessary: "If sociology is the study of society it has to take full account of those crowds of nonhumans mingled with humans. To take full account of this retinue of delegates, sociologists have to look carefully at their conflicts over who is the most representative" (1988, p. 16).

20. Like de Laet, Jonathan Murdoch (1998) finds the link between immutability and mobility overly simplified when applied to patent law. He suggests that patents perform a connection between the standardized, classificatory schemes of law or genetic science and the more fluid and heterogeneous relations of other modes of ordering. 
Hetherington suggests artifacts are more than just immutable forms of knowledge that travel through space. They transform spaces into places. ${ }^{21}$

By combining Leigh Star's and Hetherington's modifications to the concept, one can move beyond the notion that artifacts proliferate in contemporary society because knowledge must be embodied by durable materials to organize socio-technical relations. Artifacts perform place mnemonically and affectively by sustaining a multiplicity of associations with other artifacts. In this modified ANTian framework, agency is not just the capacity to stay the same, to resist "the flow", as Fuller puts it, but to multiply associations and keep them in place over time. This is a form of agency that collectives gain from artifacts as much as they do from human beings.

\section{CONCLUSION: TOWARDS ALTERNATIVE NARRATIVES OF TECHNOLOGICAL ARTIFACTS}

One of the strengths of contemporary social research on artifacts is its focus on sociocultural contexts. This attentiveness to context is a deliberate attempt on the part of cultural and social theorists to offset technological determinism and the causal roles attributed to technical artifacts in "impact narratives" (Sterne, 2005, p.7). Similarly, translation provides an antidote to other forms of reductionism, simplistic notions of causality, and impact narratives that now circulate around digital rights management, MP3s, iPods, and copyright law. The theory of translation problematizes dominant themes in studies of new technologies and artifacts such as the notion of instantaneous information transfer, direct political/ economic influences as the prime mover of technological change, and nonhuman agency as the imitation of human action. In their place, the theory of translation points us towards a cascade of increasingly simplified inscriptions, the glacial drift in the goals of prime movers, and subtle but strategic shifts of actions, capacities, and other identity attributes between heterogeneous materials. The theory of translation provides a language to describe and narrate the story of nonhuman agency in a way that offsets the explosive revolutions associated with intelligent machines like iPods and other evidently active artifacts. The agency of things in the theory of translation has less to do with automation, artificial

21."These representations assemble and transform the similitude of the materiality of space into the ordered arrangement of a place. They arrange, order, include and exclude, they make knowable a space to everyone who might choose to look at these representations and also make it possible to compare it with another space. The subjective world of memory, image, dream and fantasy, so often associated with place, operates by assembling materials into representations and using those representations to establish the difference between one place and the next. Those representations contain truth claims (not necessarily scientific) about a space" (p. 189). intelligence, or technical sophistication than it does with the continuous expansion of "social-ness" to entities that have been, and continue to be, considered "merely" technical or material. As Callon and Latour (1992) write in regards to the rather low-tech speed bump:

To claim that only the humans have meaning and intentionality and are able to renegotiate the rules indefinitely is an empty claim, since this is the very reason why the engineers, tired of the indiscipline and indefinite renegotiability of drivers, shifted their program of action to decrease this pliability. (p. 361)

Concepts like the immutable mobile and the actornetwork were useful insofar as they directed attention to the movements, circulations, and distributions across the divisions of human/nonhuman and social/ technical (Latour \& Crawford, 1993, p. 263). The notion of nonhuman agency associated with immutable mobility and actor-networks now seems problematic because it takes for granted the construction of the categories of human and nonhuman and does not emphasize the traffic between them (Reckwitz, 2002 , p. 847). If this is the case, it reinforces my argument that translation and its emphasis on the co-production of social, natural, and technological reality should be relocated to the center of ANTian understandings of artifacts.

ANT has attempted to displace the narrative of increasingly sophisticated technology with a new "mythology" about exchange of properties between human and nonhuman organization. The most significant implication for studies of artifacts - whether they be scientific, religious, or aesthetic - emerges out of this ontology symmetry; it provides a theoretical basis for re-orienting historical and cultural studies of artifacts towards the many crossovers and exchanges with nonhumans that make durable forms of social interaction possible.

\section{ACKNOWLEDGEMENTS}

I would like to thank Dr. Sheryl Hamilton, Dr. Charlene Elliott, and Dr. Paul Théberge, as well as the anonymous reviewers, for their insightful comments on earlier drafts of this article.

\section{REFERENCES}

Akrich, M., \& Latour, B. (1992). A summary of a convenient vocabulary for the semiotics of human and nonhuman assemblies. In W. Bijker \& J. Law (Eds.), Shaping technology/building society (pp. 259-264). Cambridge, Mass.: MIT Press

Barker, G. (2005, May 24). The god of iPod: Why music? The Age, 1 (cover story).

Barron, C. (Ed.). (2003). A strong distinction between humans and non-humans is no longer required for research purposes: A debate between Bruno Latour and Steve Fuller. History of the Human Sciences, 16(2), 77-99. 
Brandenburg, K. (1995). Audio coding for TV and multimedia. International Broadcasting Convention, 95, 159-164.

Bruum, H., \& Langlais, R. (2003). On the embodied nature of action. Acta Sociologica, 46(1), 31-49.

Callon, M., \& Latour, B. (1992). Don't throw the baby out with the Bath School! A reply to Collins and Yearley. In A. Pickering (Ed.), Science as practice and culture (pp. 343-360). Chicago: University of Chicago Press.

Callon, M., \& Law, J. (1995). Agency and the hybrid collectif. South Atlantic Quarterly, 94(2), 481-507.

Callon, M. (1980). Struggles and negotiations to define what is problematic and what is not: The socio-logic of translation. In K.D. Knorr, R. Krohn \& R. Whitley (Eds.), The social process of scientific investigation: Sociology of sciences, Vol IV (pp. 197-221). Dordrecht: Reidel.

Callon, M. (1986a). The sociology of an actor-network. In M. Callon, J. Law, \& A. Rip (Eds.), Mapping the dynamics of science and technology (pp. 1934). London: Macmillan.

Callon, M. (1986b). Some elements of a sociology of translation: Domestification of the scallops and fishermen of St. Brieuc Bay. In J. Law (Ed.), Power, Action, Belief A New Sociology of Knowledge? (pp. 196233). London: Routledge \& Kegan Paul.

Callon, M. (1991). Techno-economic network and irreversibility. In J. Law (Ed.), A sociology of monsters: Essays on power, technology and domination (pp. 132-161). New York: Routledge.

Callon, M., Law, J. \& Rip, A. (1986). Putting texts in their place. In M. Callon, J. Law \& A. Rip (Eds.), Mapping the dynamics of science and technology (pp. 22-130), London: Macmillan

Carey, M., \& Wall, D. (2001). MP3: The beat bytes back. International Review of Law. Computers and Technology, 15(1), $35-58$.

Casper, M. (1994). Reframing and grounding nonhuman agency: What makes a fetus an agent? American Behavioral Scientist 37(6), 839-856.

Collins, H. M., \& Yearley, S. (1992a). Epistemological chicken. In A. Pickering (Ed.), Science as practice and culture (pp. 301-326). Chicago: University of Chicago Press

Collins, H. M., \& Yearley, S. (1992b). Journey into space. In A. Pickering (Ed.), Science as practice and culture (pp. 369389). Chicago: University of Chicago Press Communications Magazine, 43(5), 90-97.

Creusere, C. D. (2003). Quantifying perceptual distortion in scalably compressed MPEG audio. Conference Record of the Thirty-Seventh Asilomar Conference on Signalsystems and Computers, 1, 265-269.

De Laet, M. (2000). Patents, travel, space: Ethnographic encounters with objects in transit. Environment and Planning D: Society and Space, 18(2), 149-168.

Egidi, L., \& Furini, M. (2005). Bringing multimedia contents into MP3 files. IEEE

Foucault, M. (1986). Of other spaces. Diacritics, 16(1), 22-27.

Hetherington, K., \& Law, J. (2000). After networks. Environment and Planning D: Society and Space, 18, 127-130.

Hetherington, K. (1997). In place of geometry: the materiality of place. In K. Hetherington \& R. Munro, Ideas of difference: Social spaces and the labor of division (pp. 183-199). Malden, MA: Blackwell.

Kahney, L. (2004, April 16). Music magic found in the shuffle. Wired News. Retrieved November 23, 2004, from http:// www.wired.com/news/culture/0,1284,63068,00.html

Knorr Cetina, K. (1997). Sociality with objects: Social relations in postsocial knowledge societies. Theory, Culture and Society, 14(4), 130.
Knorr Cetina, K., \& Bruegger, U. (2002). Traders' engagement with markets: A postsocial relationship. Theory, Culture \& Society, 19(5/6), 161-185.

Latour, B. (1986). The powers of association. In J. Law (Ed.), Power, action, belief: A new sociology of knowledge? (pp. 264-280). London: Routledge \& Kegan Paul.

Latour, B. (1987). Science in action: How to follow scientists and engineers through society. Cambridge, MA: Harvard University Press.

Latour, B. (1988). The Pasteurization of France followed by irreductions (A. Sheridan \& I. Law, Trans.). Cambridge, A Harvard University Press.

Latour, B. (1990). Drawing thing together. In M. Lynch \& S. Woolgar (Eds.), Representation in scientific practice (pp. 19-68). Cambridge, Mass.: MIT Press.

Latour, B. (1991). Technology is society made durable. In J. Law (Ed.), A sociology of monsters: Essays on power, technology and domination (pp. 103-131). New York: Routledge.

Latour, B. (1992). Where are the missing masses? A sociology of a few mundane artifacts. In W. E. Bijker, \& J. Law (Eds.), Shaping technology/building society: Studies in sociotechnical change (pp. 225-258). Cambridge, MA: MIT Press.

Latour, B. (1993). Ethnography of a high-tech case: About Armais. In P. Lemonnier (Ed.), Technological choices: transformations in material cultures since the neolithic (pp. 372398). London: Routledge.

Latour, B. (1994a). On technical mediation: Philosophy, sociology, genealogy. Common Knowledge, 3(2), 29-64.

Latour, B. (1994b). Pragmatogonies: A mythical account of how humans and nonhumans swap properties. American Behavioral Scientist, 37(6), 791-808.

Latour, B. (1996a). Do scientific objects have a history? Pasteur and Whitehead in a bath of lactic acid. Common Knowledge, 5(1), 76-91.

Latour, B. (1996b). Response: Pursuing the discussion of interobjectivity with a few friends. Mind, Culture and Activity, 3/4, 270-289.

Latour, B. (1998). How to be iconophilic in art, science, and religion. In C. Jones, \& P. Gallison (Eds.), Picturing science, producing art (pp. 418-440). London: Routledge.

Latour, B. (1999a). On recalling ANT. In J. Law \& J. Hassard (Eds.), Actor network theory and after (pp. 15-25). Oxford: Blackwell.

Latour, B. (1999b). Pandora's hope: Essays on the reality of science studies. Cambridge, MA: Harvard University Press.

Latour, B. as Johnson, J. (1988). Mixing humans with nonhumans: Sociology of a door opener. Social Problems, 35, 298-310.

Latour, B., \& Crawford, T. (1993). An interview with Latour. Configurations, 1(2), 247-269.

Latour, B., \& Woolgar, S. ([1979], 1986). Laboratory life: The construction of scientific facts. Princeton, NJ: Princeton University Press.

Law, J. (1986a). Editor's introduction: Power/ knowledge and the dissolution of the sociology of knowledge. In J. Law (Ed.), Power, action, belief: A new sociology of knowledge? (pp. 1-19). London: Routledge \& Kegan Paul.

Law, J. (1986b). On the methods of long-distance control: Vessels, navigation and the Portuguese route to India. In J. Law (Ed.), Power, action, belief: A new sociology of knowledge? (pp. 234-265). London: Routledge \& Kegan Paul.

Law, J. (1991). Introduction: Monsters, machines and sociotechnical relations. In J. Law (Ed.), A sociology of monsters: Essays on power, technology and domination (pp. 1-25). New York: Routledge. 
Law, J. (1999). After ANT: Complexity, naming, and topology. In J. Law \& J. Hassard (Eds.), Actor network theory and after (pp. 114). Oxford: Blackwell.

Lessig, L. (1999). Code and other laws of cyberspace. New York: Basic Books.

Lessig, L. (2002). The future of ideas: the fate of the commons in a connected world. New York: Vintage Books.

Murdoch, J. (1998). The spaces of actor-network theory. Geoforum, 29(4), 357-374.

Musmann, H. G. (1990). The ISO audio coding standard. Communications: Connecting the Future, GLOBECOM '90. IEEE, 1, 511-517.

Pels, D., Hetherington, K., \& Vandenberghe, F. (2002). The status of the object: Performances, mediations, and techniques. Theory. Culture \& Society, 19(5/6), 121.

Preda, A. (2000). Order with things? Humans, artifacts, and the sociological problem of rulefollowing. Journal for the Theory of Social Behaviour, 30(3), 269-298.

Rault, J. B., Dehery, Y. F., \& Lever, M. (1995). The ISO/MPEG Audio MISICAM family. IEE Colloquium on MPEG-2 - What it is and What it isn't, 3/1-3/14.

Reckwitz, \& Andreas (2002). The status of the 'material' in theories of culture: From 'social structure' to 'artefacts'. Journal for the Theory of Social Behaviour, 32(2), 195-217.

Riles, A. (2000). The network inside out. Ann Arbor: University of Michigan Press.

Ryan, M. (2003, May 11). Online music: Are we finally buying it? Chicago Tribune (Arts \& Entertainment), 1.

Schlender, B. (2001). Apple's 21st-century Walkman. Fortune Magazine, 144(9), 213-218.

Slater, D. (2002). Making things real: Ethics and order on the internet. Theory, Culture \& Society, 19(5/6), 224-245.

Smart, B. (1982). Foucault, sociology, and the problem of human agency. Theory and Society, 11(2), 121-141.

Sterne, J. (2005). The audible past: Cultural origins of sound reproduction. Durham, NC \& London: Duke University Press.

Thorwirth, N. J., Horvatic, P., Weis, R., \& Jian Zhao (2000). Security methods for MP3 music delivery. Conference Record of the Thirty- Fourth Asilomar Conference on Signals, Systems and Computers, 2, 1831-1835.

Thrift, N. (1999). The place of complexity. Theory, Culture and Society, 16, 31-70.

Vedres, B., Bruszt, V., \& Stark, D. (2005). Organizing technologies: Genre forms of online civic association in Eastern Europe. Annals of the American Academy of Political and Social Science, 597(1), 171-188.

Walker, L. (2004, Feb 1). The cola giants align with music vendors. Washington Post, F07.

Winner, L. (1980). Do artifacts have politics? Daedalus, 109(1), $121-136$

\section{CORRESPONDENCE}

John Shiga, Ph.D. Candidate,

School of Journalism \& Communication,

Carleton University,

1125 Colonel By Drive,

Ottawa, ON, K1S 2H4,

Canada.

E-mail:jshiga@connect.carleton.ca

Published online 2006-04-21

ISSN 1749-3463 print/ ISSN 1749-3471

DOI: 10.1080/17493460600658318

(C) 2007 Artifact 